\title{
Olfactory systems across mosquito species
}

\author{
Matthew Wheelwright ${ }^{1}\left[\right.$ Catherine R. Whittle ${ }^{1}\left(\mathbb{D} \cdot\right.$ Olena Riabinina $^{1}(\mathbb{C}$
}

Received: 29 September 2020 / Accepted: 15 December 2020 / Published online: 21 January 2021

(c) The Author(s) 2021

\begin{abstract}
There are 3559 species of mosquitoes in the world (Harbach 2018) but, so far, only a handful of them have been a focus of olfactory neuroscience and neurobiology research. Here we discuss mosquito olfactory anatomy and function and connect these to mosquito ecology. We highlight the least well-known and thus most interesting aspects of mosquito olfactory systems and discuss promising future directions. We hope this review will encourage the insect neuroscience community to work more broadly across mosquito species instead of focusing narrowly on the main disease vectors.
\end{abstract}

Keywords Receptors $\cdot$ Neurons $\cdot$ Olfactory organs $\cdot$ Brain $\cdot$ Evolution $\cdot$ Sensory ecology $\cdot$ Neuroethology $\cdot$ Mosquitoes

\section{Introduction}

Pick up any paper about mosquitoes and the first sentence of it will tell you about the diseases and deaths that mosquitoes bring to humans. It is no wonder then that most of the mosquito research so far has focussed on the species that transmit diseases, such as Anopheles gambiae, Aedes aegypti, Culex quinquefasciatus and a handful of other common disease vectors. But this is only a part of the story-out of $3500+$ mosquito species (Harbach 2018) separated by up to 145-200 million years of evolution (Chen et al. 2015; Hao et al. 2017) most do not transmit diseases and many are not interested in humans (e.g., Reeves et al. 2018) or do not bloodfeed altogether (Miyagi 1981; O’Meara 1985; Rattanarithikul et al. 2007). The part of their olfactory repertoire devoted to host-seeking is likely to differ between these species (Wolff and Riffell 2018). Another part, dedicated to finding flowers for nectar feeding, will be adapted to recognise the volatiles from the flowering plants available in the species' habitat (Nikbakhtzadeh et al. 2014; Zeng et al. 2019; Peach et al. 2019; Lahondère et al. 2019; Dekel et al. 2019a). The factors that determine an ideal oviposition site are also different-the absence of predator hydrocarbons for Culiseta longiareolata

Matthew Wheelwright and Catherine R. Whittle contributed equally to this work.

Olena Riabinina

olena.riabinina@durham.ac.uk

1 Department of Biosciences, Durham University, Stockton Road, Durham DH1 3LE, UK
(Silberbush et al. 2010), bacterial volatiles for Aedes aegypti (Ponnusamy et al. 2008) and a leaf of the host pitcher plant for Wyeomyia smithii (Heard 1994). The most overlooked aspect of mosquito ecology-pheromones-is now receiving more attention (Mozūraitis et al. 2020) and some of these pheromones are likely to be strongly species-specific. Finally, larval mosquitoes also employ olfaction to recognise a variety of odorants (Xia et al. 2008; Sun et al. 2020a) the ecological relevance of which is still largely unknown.

Studying the olfactory systems of mosquitoes allows us to develop specific smell-based traps and repellents for those species that transmit deadly diseases. Equally, mosquitoes present us with unique opportunities to study unexplored processes that regulate olfactory sensitivity, rapid evolution of olfactory receptors and olfactory signals (Neafsey et al. 2015), relations between olfaction and speciation (Coetzee et al. 2013; Bradshaw et al. 2018) and the effect of climate change, urbanisation and invasions on sensory systems (Balkew et al. 2020; Rose et al. 2020). We may wish to look beyond the olfactory receptors and study the processing of signals in the mosquito brain, which opens up a whole new set of questions concerning multisensory integrations and feedbacks (Vinauger et al. 2019), the importance of trade-offs between brain areas devoted to different sensory modalities (Keesey et al. 2019) and the effects of learning (Lutz et al. 2017; Vinauger et al. 2018; Wolff et al. 2019).

In this review, we do not aim to provide a comprehensive summary of mosquito olfactory research to date. Instead, we aim to highlight the least explored and most fascinating 

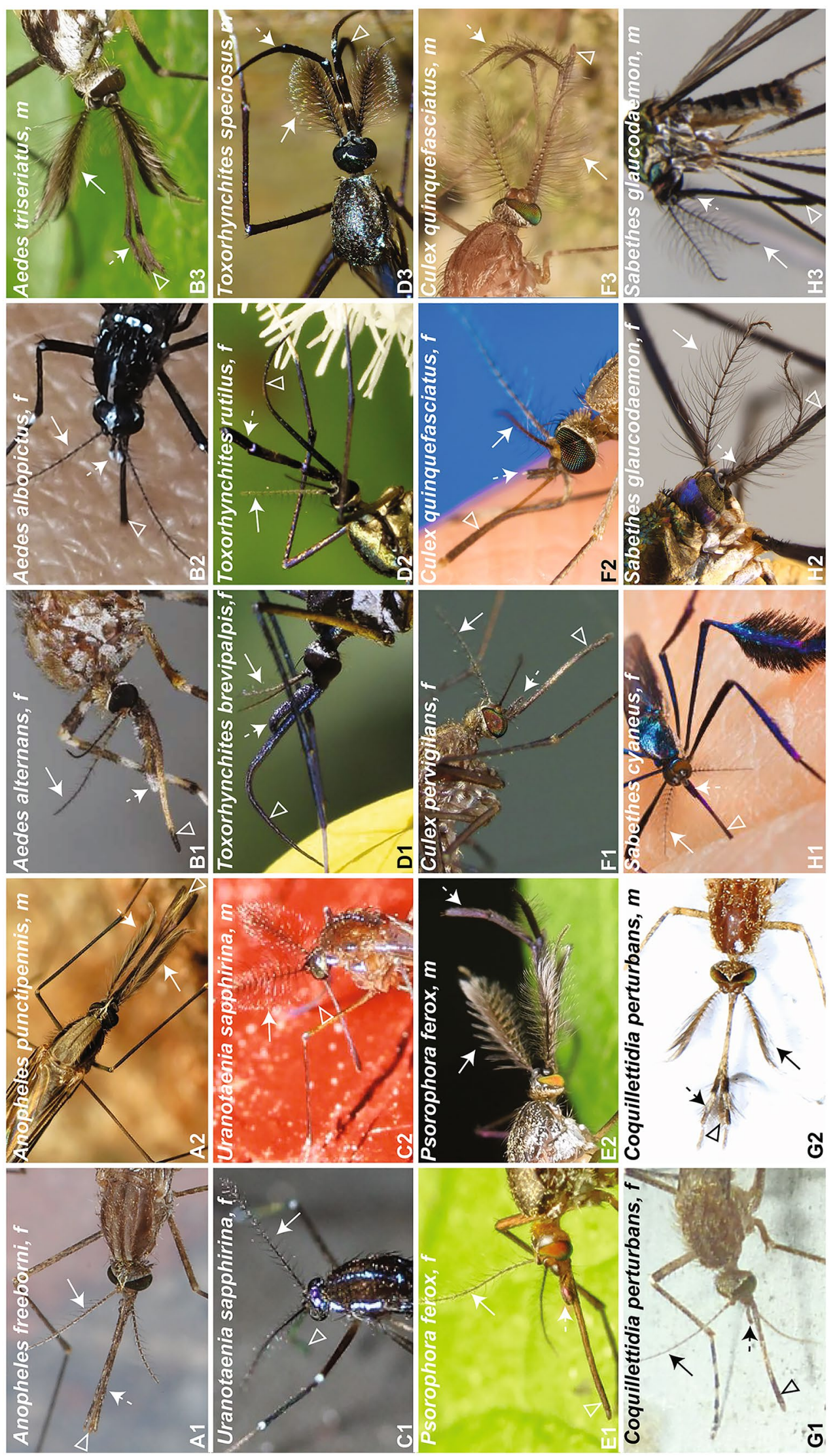
४Fig. 1 Olfactory organs of mosquitoes. Solid arrows point to antennae, dashed arrows point to maxillary palps, arrowheads point to proboscises. $\mathrm{f}$-female, $\mathrm{m}$-male. Image credits: A1. Anopheles freeborni female (https://www.inaturalist.org/observations/171373, Don Loarie), A2. Anopheles punctipennis male (https://www.inaturalist.org/observations/ 48198941, Katja Schulz), B1. Aedes alternans female (https://www. inaturalist.org/observations/50594863, Wendy Moore), B2. Aedes albopictus female (https://www.inaturalist.org/observations/32721364, Zygy), B3. Aedes triseratus male (https://www.inaturalist.org/observations/ 44504824, skitterbug); C1. Uranotaenia sapphirina female (https://www. inaturalist.org/observations/50204034, Arturo Santos), C2. Uranotaenia sapphirina male (https://www.inaturalist.org/observations/24801804, Even Dankowicz), D1. Toxorhynchites brevipalpis female (https://www. inaturalist.org/observations/45377361, Alan Manson), D2. Toxorhynchites rutilus female (https://www.inaturalist.org/observations/21372632, Katja Schulz), D3. Toxorhynchites speciosus male (https://www.inaturalist. org/observations/18770512, Steve Kerr); E1. Psorophora ferox female (https://www.inaturalist.org/observations/20379672, Katja Schulz), E2. Psorophora ferox male (https://www.inaturalist.org/observations/9620348, skitterbug), F1. Culex pervigilans female (https://www.inaturalist.org/ observations/54584455, Steve Kerr), F2. Culex quinquefasciatus female (https://phil.cdc.gov/Details.aspx?pid=4734, James Gathany), F3. Culex quinquefasciatus male (https://www.inaturalist.org/observations/23073942, skitterbug); G1. Coquillettidia perturbans female (https://www.inaturalist. org/observations/19518594, Even Dankowicz), G2. Coquillettidia perturbans male (https://www.inaturalist.org/observations/6867156, Judy Gallagher), H1. Sabethes cyaneus female (https://phil.cdc.gov/Details. aspx?pid=20514, James Gathany), H2. Sabethes glaucodaemon female, and H3. Sabethes glaucodaemon male (both Image library of Coleção de Culicidae-Fundação Oswaldo Cruz, Rio de Janeiro, Brazil (CCULI))

facts and phenomena that we believe will define the future research on mosquito olfaction. We are, of course, biased.

\section{Olfactory organs}

Olfactory perception in mosquitoes and other insects starts from their peripheral olfactory organs. These are traditionally defined by the expression of olfactory receptors (see the "Olfactory receptors" section below), neuronal responses and contribution to behavioural responses to airborne odorants. In adult mosquitoes, olfactory receptor expression has been localised to the antennae, maxillary palps and proboscis in Anopheles (Pitts et al. 2004, 2011; Athrey et al. 2017; Saveer et al. 2018), Aedes (Melo et al. 2004; Bohbot et al. 2007; Sparks et al. 2014; Matthews et al. 2016; Lombardo et al. 2017), Toxorhynchites (Zhou et al. 2014 (only antenna and maxillary palps were studied)) and Culex (Xia and Zwiebel 2006; Leal et al. 2013), implying that all three of these are peripheral olfactory organs. Electrophysiological and behavioural experiments support this conclusion (e.g., Kwon et al. 2006; Ghaninia et al. 2008; Saveer et al. 2018).

The overall morphology of adult mosquito antennae and maxillary palps is similar across species, often with pronounced sexual dimorphisms. For example, males of Aedes, Anopheles, Coquillettidia, Culex, Psorophora and Toxorhynchites species have large bushy antennae (Fig. 1, A1-G2) whereas females of the same species have more slender antennae. Interestingly, antennal sexual dimorphisms are minimal in some species, such as Sabethes mosquitoes (Fig. 1, H1-H3). Apart from having an olfactory function, antennae also mediate sound detection in mosquitoes (e.g., Warren et al. 2010; Lapshin 2012; Windmill et al. 2018; Su et al. 2018) and the evolution of overall antennal morphology has most likely been driven by demands of both olfaction and hearing.

The overall morphology of maxillary palps differs across species and between sexes. For example, male Anopheles have long club-shaped maxillary palps, whereas females have cylindrical palps that are slightly shorter than those of males (Fig 1, A1-A2). Sabethes' palps are very short and similar in males and females (Fig. 1, H1-H3) In Aedes, Culex, Toxorhynchites and Psorophora males sport elaborate maxillary palps that curve upwards, whereas females have straight maxillary palps that are much shorter than the proboscis (Fig 1, B1-B3 and D1-F3). Maxillary palps carry chemosensory sensilla and mechanosensory bristles and are thus, like antennae, both olfactory and mechanosensory organs (McIver 1971; McIver and Hudson 1972). However, mechanosensitivity is accomplished at the level of individual sensilla and not the entire organ, as is the case for antennae. The role of different maxillary palp morphologies thus remains unclear.

The morphology of the proboscis presents the most interesting case of the three olfactory organs and is related to the role of the proboscis in blood intake. The mosquito proboscis usually consists of 6 organs (a pair of maxillae with teeth-like structures, a pair of mandibles, a needle-like labrum and a hypopharynx) encased in a labium that ends in a labellum (see e.g., Fig. 1 in Choo et al. 2015). In females of blood-feeding species, all 6 organs are about the same length as the labium and they enter the skin during blood-feeding. The length of the maxillae and mandibles varies in males of these species (Wahid et al. 2003), and stylet innervation is strongly sexually dimorphic in Aedes aegypti (Jové et al. 2020). The males of blood-feeding species are not able to pierce skin and do not blood-feed. In fact, blood significantly reduced the survival of male Culex quinquefasciatus in a laboratory experiment (Nikbakhtzadeh et al. 2016). Interestingly, both males and females of non-bloodfeeding Malaya and Topomyia species have completely lost both mandibles and maxillae (Wahid et al. 2003). The proboscises of some non-bloodfeeding species have strikingly different morphologies compared with bloodfeeding mosquitoes. For example, Malaya mosquitoes have an unusual proboscis, enlarged at its distal end (Rattanarithikul et al. 2007). These mosquitoes feed on bamboo juice that they obtain via trophallaxis from Crematogaster ants (Miyagi 1981). Toxorhynchites mosquitoes also do not feed on blood and have a very distinct long curved proboscis (Fig. 1, D1-D3) presumably to facilitate nectar feeding from plants. 
The appearance of the labium is similar between males and females of blood-feeding species (Fig. 1). In addition, in Anopheles gambiae females, the proboscis is connected by a dense cuticle to the posterior surface of the head capsule, whereas in males it is not connected (OR, personal observation). This anatomical feature presumably helps to exert the necessary force to insert the stylet into and extract it from, the skin. Labella of Anopheles gambiae harbour equal numbers of olfactory sensory neurons (OSNs) in males and females (Riabinina et al. 2016).

The antennae, maxillary palps and proboscis are not functionally equivalent substrates for their olfactory neurons. The differences lie in the patterns of brain innervation (see "Structure and function of the antennal lobe and subesophageal zone" below) and in the specific groupings of olfactory neurons within their sensilla (see "Inhibition in the peripheral olfactory system: mechanisms and ecological relevance" below). In addition, morphologically different types of olfactory sensilla cover the three organs (e.g., McIver 1971; McIver and Hudson 1972; Khalifa et al. 2013), although the importance of sensillar morphology remains unclear.

Mosquito larvae also exhibit chemosensory behaviours and express olfactory receptors (Bohbot et al. 2007; Xia et al. 2008; Liu et al. 2010; Scialò et al. 2012; Bui et al. 2019; Melo et al. 2020; Lutz et al. 2020; Sun et al. 2020a). Anopheles gambiae harbour olfactory neurons in their antennae and maxillary palps (Xia et al. 2008; Riabinina et al. 2016; Sun et al. 2020a). In contrast to adult mosquitoes, in the larvae the number of neurons and the overall anatomy of antennae and maxillary palps are not sexually dimorphic in this species (O.R., personal observation). Indeed, the ecological needs of male and female larvae of Anopheles gambiae are likely to be identical. It would be very interesting to explore the anatomy of the larval olfactory systems in mosquito species that do not blood-feed. In these species, the nutrient accumulation needed for egg production is shifted to the larval stage and thus, female larvae have potentially different needs to the male ones.

There have been no reports of olfactory behaviours in mosquito pupae that are, like larvae, aquatic and mobile but in contrast to larvae do not feed.

\section{Olfactory receptors}

\section{Types of olfactory receptors and chemosensory proteins in mosquitoes}

Olfactory receptor genes have been identified and annotated, to a varying extent, in the genomes of 2 Aedes, 19 Anopheles and 1 Culex species (https://vectorbase.org/) but this list is growing continuously. Additional information about mosquito receptors comes from gene expression studies, e.g., in Toxorhynchites amboinensis (Zhou et al. 2014) and Anopheles coluzzii (Athrey et al. 2017). Comparative analysis of Anopheles genomes found that chemoreceptor genes in these species are among the fastest evolving (Neafsey et al. 2015). At the same time, the odorant receptor-coreceptor ORCO is very highly conserved in insects (Missbach et al. 2014) and is the only chemoreceptor with a known 3D structure (Butterwick et al. 2018).

The three main classes of receptors involved in mosquito olfaction, similarly to other insects, are gustatory receptors (GRs), ionotropic receptors (IRs) and odorant receptors (ORs) (e.g., Leal 2013; Suh et al. 2014). IRs and ORs are sensitive to a range of odorants (e.g., Xia et al. 2008; Carey et al. 2010), whereas the role of GRs in olfaction is limited to the detection of $\mathrm{CO}_{2}$ and other volatile odorants via a heterotrimeric complex made up of G1, G2 and G3 in Aedes sp. and Culex sp. and G22, G23 and G24 in Anopheles sp. (Hill et al. 2002; Robertson and Kent 2009; Tauxe et al. 2013; Younger et al. 2020). Transient receptor potential channels (TRPs), sensory neuron membrane proteins (SNMPs) and pickpocket (ppk) ion channels are also expressed in the chemosensory organs of Aedes aegypti (Bohbot et al. 2014; Tallon et al. 2019), Culex quinquefasciatus (Leal et al. 2013; Taparia et al. 2017) and Anopheles gambiae (Zelle et al. 2013), although their role in mosquito olfactory processing is not yet established. Odorant binding proteins (OBPs), chemosensory proteins (CSPs) and Che A/B proteins are involved in olfactory processing in other insects and may also play an olfactory roles in mosquitoes (Ben-Shahar et al. 2010; Leal 2013; Bohbot et al. 2014).

\section{Receptor expression and co-expression: novel findings}

ORCO expression patterns have been studied in adult and larval Anopheles gambiae (Xia et al. 2008; Riabinina et al. 2016) and Aedes aegypti (Melo et al. 2004; Degennaro et al. 2013; Won Jung et al. 2015) by employing immunohistochemistry, in situ hybridisation and genetic tools. The same methods were used to establish expression patterns of GR4 and IR7a in Aedes aegypti (Jové et al. 2020). These works established expression of odorant receptors in the antennae, maxillary palps and proboscis of mosquitoes, in line with electrophysiological recordings (Kwon et al. 2006; Qiu et al. 2006; Lu et al. 2007). However, it remained unclear whether ORs, IRs and GRs are expressed in separate groups of neurons or if they may be co-expressed in the same cell. A large body of work in Drosophila argues for separate expression patterns (e.g., Benton et al. 2009), with very few exceptions (Dobritsa et al. 2003; Goldman et al. 2005; Couto et al. 2005; Fishilevich et al. 2005). This conclusion has been challenged by recent intriguing findings in Drosophila that 
IR and OR receptors are very broadly co-expressed and occur in the same neurons (Task et al. 2020). This is also true for Aedes aegypti mosquitoes (Younger et al. 2020), which has extensive implications relating to the processing of naturally occurring odorant mixtures, such as human body odor, which activate both OR (McBride et al. 2014) and IR receptors (Pitts et al. 2017).

A drastic difference in the expression of chemosensory proteins can be seen between larvae and adult mosquitoes. Possibly because of their reduced suite of olfactory-based behaviours, larvae show a smaller repertoire of expressed olfactory receptors. For example, whereas the adults of Anopheles gambiae and Aedes aegypti express 79 and 80 ORs respectively (Hill et al. 2002; Ruel et al. 2019), their larvae have a much smaller repertoire with Anopheles gambiae expressing 12 ORs (4 of which are larval specific) and at least 4 IRs (Xia et al. 2008; Liu et al. 2010) and Aedes aegypti expressing 23 ORs (15 of which are larval specific) (Bohbot et al. 2007) in their antennae. ORCO is also expressed in the maxillary palps of Anopheles gambiae larvae (Riabinina et al. 2016) but expression of other ORs has not been studied in this chemosensory organ.

A recent paper on Anopheles gambiae described an interesting feature of mosquito ORs, which is not shared by Drosophila (Maguire et al. 2020). This study focused on AgOR2, a receptor that is sensitive to indole, phenols, benzaldehyde and other aromatic compounds and is highly conserved between mosquito species (Carey et al. 2010; Bohbot et al. 2011). When AgOR2 was ectopically expressed in ORCO-positive olfactory sensory neurons where their native ORs were already present, the original ORs (but not ORCO) were downregulated and the ectopic OR2 was also not functional, leading to a total loss of odorant sensitivity in the ORCO neurons (Maguire et al. 2020). This finding suggests a fine-tuned mechanism that regulates expression levels of ORs in Anopheles gambiae and is disrupted by unnaturally high levels of OR2 protein. While in Anopheles gambiae OR2 overexpression or ORCO mutation does not lead to dramatic reduction of the size of the antennal lobe (Maguire et al. 2020; Sun et al. 2020b), ORCO mutation affects antennal lobe size in clonal and ponerine ants (Trible et al. 2017; Yan et al. 2017; Ryba et al. 2020) and, to a lesser extent, in the moth Manduca sexta (Fandino et al. 2019). It therefore appears that there is a continuous spectrum of ORCO-OR function-ORN development interactions amongst insects, despite high conservation of ORCO. In mammals, OR expression is also crucial for the development of olfactory neurons and allows for correct mapping to the corresponding regions of the olfactory bulb (e.g., Lodovichi and Belluscio 2012).

Even more intriguing is that, unlike in Drosophila (with a few notable exceptions (Vosshall and Stocker 2007)), the olfactory neurons of some mosquitoes naturally co-express several odorant receptors. For instance, one neuronal type in the blunt trichoid sensilla of Anopheles gambiae co-expresses AgOR13, AgOR15, AgOR17 and AgOR55 (Schultze et al. 2014; Karner et al. 2015) and around half of these neurons also express AgOR16 and AgOR47, which means that some neurons can express up to six different olfactory receptors in the same cell (Karner et al. 2015). It is possible that the receptor interaction feedback system is only active after a receptor has been translated (Maguire et al. 2020). Since the 6 naturally co-expressed ORs form a gene cluster (Karner et al. 2015), they share the same regulatory elements and are all transcribed onto the same polycistronic mRNA (Karner et al. 2015), thus avoiding downregulation by the feedback system (Maguire et al. 2020). The prevalence of OR gene clusters in the genomes of mosquitoes could therefore be essential for functional expression of ORs (Fox et al. 2002; Hill et al. 2002).

\section{Enantio-selectivity}

Some mosquito ORs show enantio-selectivity, which means that they have different affinities to the two forms, R and $\mathrm{S}$, of a chiral molecule (Bohbot and Dickens 2009; Cook et al. 2011; Dekel et al. 2016; Huff and Pitts, 2019). For instance, cells expressing AgOR29 in Anopheles gambiae show a larger response to a mixture of (R)-(-)- and (S)-(+)-linalool compared with (R)-(-)-linalool alone. This suggests that AgOR29 is more sensitive to (S)-(+)-linalool than to (R)-(-)-linalool (Huff and Pitts 2019). In contrast, AaOR8 of Aedes aegypti is more sensitive to (R)-1-octen-3-ol than to (S)-1-octen-3-ol (Bohbot and Dickens 2009), which translates to a larger neuronal response to (R)-1-octen-3-ol than to (S)-1-octen-3-ol as well as a behavioural preference (Cook et al. 2011). This increased sensitivity to (R)-1-octen3-ol is shared by Culex quinquefasciatus (Cook et al. 2011). In contrast to Aedes aegypti, Culex quinquefasciatus shows a higher aversion to (R)-1-octen-3-ol (Cook et al. 2011). The difference in the behavioural valence of 1-octen-3-ol may be due to the fact that it is an important host cue for mosquitoes. Interestingly, cattle produce $80-92 \%$ of (R)-1-octen-3-ol and 8-20\% of (S)-1-octenol (Hall et al. 1984). Mosquitoes that feed on mammalian hosts, such Aedes aegypti, may thus have evolved attraction to it, whereas species that feed on avian hosts, such as Culex quinquefasciatus, are repelled by it (Cook et al. 2011). However, the OR8 of Toxorhynchites amboinensis is also enantio-selective and shows increased sensitivity to (R)-1-octen-3-ol (Dekel et al. 2016) despite the fact that this species does not feed on blood (Collins and Blackwell 2000). (R)-1-octen-3-ol could potentially be produced more than (S)-1-octen-3-ol by other sources of 1-octen-3-ol in the environment, such as flowering plants (Knudsen et al. 1993; Syed and Guerin 2004). For example, one plant species, Lantana camara, produces a mixture consisting of 95\% (R)-1-octen-3-ol and 5\% (S)-1-octenol 
(Syed 2002; Syed and Guerin 2004). While we do not know whether 1-octen-3-ol is produced by plants on which Toxorhynchites sp. feeds, there have only been a few observations of Toxorhynchites sp. feeding as adults (Collins and Blackwell 2000). It is possible that floral compounds consisting of more (R)-1-octen-3-ol than (S)-1-octenol could lead to the enantio-selectivity of OR8. It would be interesting to explore enantio-selectivity and its ecological significance for other mosquito ORs.

\section{Chemosensory proteins: OBPs and CheA/B}

The ability for a mosquito to detect an odorant depends not only on the receptors expressed in the olfactory sensory neurons but also on accessory proteins in the perireceptor environment. In a sensillum, dendrites of olfactory sensory neurons are surrounded by an aqueous solution known as the sensillar lymph (Ishida et al. 2002). Hydrophobic odorants are insoluble in the lymph and thus need to be transported by another molecule to the receptor binding sites. This is done by odorant binding proteins (OBPs) (Leal 2013).

The role of OBPs was investigated in Culex quinquefasciatus where it was found that CquiOBP1 RNAi knock-down reduced the EAG responses to the mosquito oviposition pheromone (MOP) and indole by half (Pelletier et al. 2010). Similarly, knockdown of AgambOBP1 in Anopheles gambiae (Biessmann et al. 2010) and Obp37/39 in Aedes albopictus (Deng et al. 2013) abolished EAG responses to indole. OBP genes and transcripts have been also identified in Aedes aegypti (Zhou et al. 2008; Sengul and Tu 2010), Anopheles sinensis (He et al. 2016), Anopheles stephensi (Sengul and Tu 2008), Anopheles quadriannulatus (Sengul and Tu 2008), Anopheles arabiensis (Li et al. 2005), Anopheles culicifacies (Das et al. 2018) and Anopheles funestus (Xu et al. 2010), often expressed outside of the chemosensory organs per se. While there is no doubt that OBPs can bind odorants (a property that has been utilised for chemical detector devices (e.g. Cali and Persaud 2020), the role of OBPs in the insect olfactory system is less well understood. For example, Drosophila ab8 sensilla that normally express Obp28a retained or even increased their sensitivity to odorants after Obp28a knock-out (Larter et al. 2016). This result was supported by a subsequent study in Drosophila that found that basiconic sensilla showed no reduction in response to odorants when all their native OBPs were not expressed (Xiao et al. 2019). Pairing between OBPs/OBPs and OBPS/ORs is another unresolved puzzle that has been studied in Anopheles gambiae (Schultze et al. 2013) and Drosophila melanogaster (summarised in Xiao et al. 2019). OBPs may be expressed alone or co-expressed in various combinations of up to 4 OBPs that do not have a one-to-one correlation with OR expression patterns.
It appears that not all OBPs are the same: some of them have an essential function in the olfactory system, some have a modulatory function and some-no function. The structure of the sensilla themselves may provide one of the answers to this puzzle, as sensillar pore tubules in some sensilla dramatically reduce the travel path of an odorant through the lymph and thus the role of OBPs in these sensilla (Larter et al. 2016). Another possibility may lie in the structure of OBPs: currently, OBPs are separated into Classic, Minus-C, Plus-C and Atypical/two-domain categories based on the number of cysteine residues they contain (Manoharan et al. 2013). Indeed, apart from capturing odorant molecules, OBPs are also involved in odorant release, development regeneration, and other processes (Pelosi et al. 2018).

Another group of accessory proteins that are potentially involved in chemosensation are Che $\mathrm{A}$ and CheB proteins. These proteins were mainly studied in Drosophila but 3 members of this gene family are expressed in the antennae and maxillary palps of Aedes albopictus (AALF012531, AALF021726 and Ae2-204624_FR6_8-206) (Lombardo et al. 2017) and 13 (10 CheA and 3 CheB proteins) are expressed in the maxillary palps of Aedes aegypti (Bohbot et al. 2014). These proteins are involved in the perception of cuticular hydrocarbons during courtship in Drosophila (Park et al. 2006). However, there is evidence for (Park et al. 2006) and against (Lin et al. 2005; Ben-Shahar et al. 2010) the role of these proteins in fly mating behaviour. While the molecular function of Che A/B proteins is not known definitively (Lombardo et al. 2017), they could interact with DEG/EnaC channels to modulate their responses (BenShahar et al. 2010).

\section{Evolution of olfactory receptors}

The expression and rapid evolution of chemosensory proteins in mosquitoes often parallels the ecological relevance of chemicals that the proteins bind. For example, several studies have focused on the differences between anthropophilic and zoophilic Aedes mosquitoes (McBride et al. 2014). Aedes aegypti aegypti feeds on humans, while its forest-dwelling counterpart Aedes aegypti formosus is zoophilic (McBride et al. 2014) and inhabits forest areas of Africa, sometimes close to the human dwellings where Aedes aegypti aegypti is found (Rose et al. 2020). The two species may be found sympatrically in man-made habitats (Futami et al. 2020). AeOR4 receptor detects sulcatone, the prevalent component of human odour and is upregulated in the Aedes aegypti aegypti compared with Aedes aegypti formosus (McBride et al. 2014). The genetic differences between the two subspecies are focused in the region of chromosome 1 where the AeOR4 gene locus is located (Rose et al. 2020). Similarly, populations of Aedes albopictus, which have been moved to novel areas through human activity, 
show upregulation of OR100 and OR47-N2 compared with predominantly zoophilic populations from its native range (Gomulski et al. 2020). Aedes aegypti homologs of these receptors are upregulated in anthropophilic Aedes aegypti aegypti, suggesting that increased sensitivity to human odors may play a role in adaptations to new environments. It would be intriguing to investigate whether the recent spread of Asian Anopheles stephensi to the Horn of Africa (Seyfarth et al. 2019; Balkew et al. 2020) has been accompanied by a similar upregulation of ORs and IRs sensitive to humanderived volatiles.

To examine the olfactory repertoires of species that display a wider diversity of life history traits, recent studies compared mosquito species that feed on blood and those that do not, such as Toxorhynchites amboinensis (Zhou et al. 2014; Dekel et al. 2016, 2019b, a). These studies identified ORs that are most highly conserved among species: OR2 and OR 10. These receptors detect indole and skatole, compounds derived from animal hosts, plants for nectar feeding and suitable oviposition sites (Dekel et al. 2019b). They are also important odorants for larvae since Aedes aegypti larvae express OR2 in their antennae along with another supersensitive, larval-specific, skatole receptor, AeOR9 (Ruel et al. 2019). Surprisingly, Toxorhynchites amboinensis expresses a receptor for sulcatone (TambOR4) despite not feeding on blood (Dekel et al. 2019a), which highlights the possibility that sulcatone is potentially used for behaviours other than host-seeking (Dekel et al. 2019a). Further studies could not only provide a better idea of the ecological relevance of many odorants but could also provide an insight into the evolutionary history of mosquito olfactory systems by identifying other odorant receptors that are highly conserved among species.

\section{Neurons and brain}

\section{Inhibition in the peripheral olfactory system: mechanisms and ecological relevance}

Responses of olfactory receptor neurons in Drosophila (e.g., Wilson 2013) and mosquitoes (e.g., Qiu et al. 2006; Ghaninia et al. 2007) are defined by the receptors they express. Neurons that occupy the same sensillum also modulate each other's responses-a phenomenon known as lateral, or ephaptic, inhibition (Su et al. 2012). In the rare cases when two different functional odorant receptors co-exist in the same neuron, the responses of the neuron to an odorant may depend on both receptors. We name this phenomenon "intraneuron interaction" (Xu et al. 2019). Additionally, the nature of chemical ligands that bind to a receptor affects the receptor's conductivity and its response to ligands-we call this "intrareceptor interaction" (Xu et al. 2019).
The process of lateral inhibition was initially investigated in Drosophila, looking at the ab3 sensillum ( $\mathrm{Su}$ et al. 2012). In one experiment, a background odorant, methyl hexanoate, was supplied to stimulate sustained firing of one neuron (ab3A), whilst an odor pulse of 2-heptanone was simultaneously supplied to a neighbouring neuron (ab3B). Addition of the superimposed odor pulse substantially reduced the recorded response from ab3 $\mathrm{A}$ in a dosedependent manner. However, inhibition was not observed when ab3B was genetically ablated, ruling out direct inhibition at the receptor level. Repeating this procedure using capitate peg sensilla in Anopheles gambiae maxillary palps, with $\mathrm{CO}_{2}$ as the background odorant and 1-octen3-ol superimposed, yielded the same effect (Su et al. 2012). Supporting results were found through testing a diverse range of Drosophila sensilla types (large basiconic, small basiconic, coeloconic and trichoid sensilla) with up to four ORNs each (Su et al. 2012). Furthermore, different species with compartmentalised receptor neurons, such as beetle sensilla, have demonstrated inhibitory effects (Nikonov and Leal 2002). These findings taken together suggest that lateral inhibition is a robust and broadly observed phenomenon among insects and plays an important role in the olfactory system of various mosquito species.

There remains debate over the mechanism for lateral inhibition; however, it is thought unlikely that synapses or gap junctions are involved; ephaptic transmission, also known as ephaptic coupling, seems to offer a more plausible explanation (Su et al. 2012; Xu et al. 2019; Pannunzi and Nowotny 2020). The extracellular electrical potential of a sensillum's microenvironment (the sensillar lymph) is affected by ion flows, particularly the movement of cations into the neuron during depolarisation. Changes to this extracellular electric field influence the membrane potential and therefore the occurrence of action potentials of neurons within the same sensillum, meaning a neuron is suppressed through hyperpolarisation if a co-located neuron is activated (van der Goes van Naters 2013). Research in Drosophila (Zhang et al. 2019) has expanded on the proposed mechanism, suggesting an asymmetry in lateral inhibition, whereby the dominant ORN in a sensillum, that being the bigger neuron with characteristically larger spike amplitudes, exerts greater ephaptic effects and is less sensitive to them from other neurons. As such, the less dominant neuron has a reduced likelihood of reaching the action potential threshold when the more dominant ORN is stimulated (Zhang et al. 2019). It is generally observed across insect species that dominant neurons detect attractive odorants and non-dominant neurons detect aversive odorants ( $\mathrm{Ng}$ et al. 2020). Sensilla are also thought to be organised antagonistically such that their ORNs detect stimuli from ecologically related sources that require opposing behavioural responses; for example ab4A and ab4B neurons in Drosophila promote and inhibit egg laying respectively ( $\mathrm{Ng}$ et al. 2020). 
At a more peripheral level there is evidence, though limited, that intrareceptor and intraneuron inhibition modulate odor responses ( $\mathrm{Xu}$ et al. 2019). One receptor in Culex quinquefasciatus, CquiOR32, generates excitatory (inward) currents when activated by a range of ligands, such as cyclohexanone, methyl salicylate and 2-methyl-2thiazoline. However, inhibitory (outward/reverse) currents are also elicited in this same receptor in a dose-dependent manner by a range of odorants including artificial insect repellents DEET and IR3535, as well as fenchone and eucalyptol (Xu et al. 2019). The authors reason that the chemical dissimilarity between agonists and inhibitors means it is unlikely that both bind to the same orthosteric receptor site, so suggest the involvement of an allosteric modulator (Xu et al. 2019). The exact mechanism remains unknown, though it is possible that inhibitory ligands cause the closing of certain channels that would usually be open to allow an anion influx and depolarisation. Alternatively, they may cause an influx of cations, with $\mathrm{Cl}^{-}$a proposed candidate for involvement ( $\mathrm{Xu}$ et al. 2019).

Intraneuron inhibition occurs when multiple receptors in the same neuron interact with each other. Experiments with transgenic Drosophila that ectopically expressed Culex receptor CquiOR32 in all ORCO+ neurons demonstrated that eucalyptol-induced inhibitory currents through CquiOR32 cancelled out excitatory methyl salicylate-induced currents through DmelOR98a (Xu et al. 2019). Similar effects were observed during SSR recordings in Culex quinquefasciatus and Aedes aegypti SST2 sensilla in response to excitatory cyclohexanone and inhibitory eucalyptol (Xu et al. 2019). It is worth noting that this type of inhibition relies on a single neuron expressing multiple different receptors, a phenomenon subject to current debate but thought to occur very rarely in flies and more frequently in mosquitoes (see Receptor expression and co-expression: novel findings) (Karner et al. 2015).

The inhibitory mechanisms described here have a range of possible advantages, particularly concerning mixture processing. Mixtures have an emergent perceptual quality, meaning that an ORN's response to a mixture cannot necessarily be predicted by summing the ORN's responses to that mixture's individual components. Inhibitory effects enhance the dynamic range of ORN responses to aid in accurately determining concentration ratios of odors of mixtures (Pannunzi and Nowotny 2020). Another challenge of mixture perception is distinguishing between odors from a single source and odors that emanate from different sources (Pannunzi and Nowotny 2020). An odor plume is composed of filaments such that odorants from co-localised sources are found in the same filaments, whilst those from separate sources reach the receptors in different filaments. Therefore, only odors from a single source are sufficiently spatially and temporally synchronised to cause depolarisation of their corresponding ORNs sufficiently close together for ephaptic effects to exert an influence (Murlis et al. 1992). Furthermore, the unique temporal dynamics of ORN response spikes allow mixtures of compounds that promote excitatory and inhibitory responses to be distinguished from a single excitatory stimulus of lower intensity, regardless of stimulus duration or concentration (Su et al. 2011). Inhibitory effects may also aid in suppressing sustained but irrelevant, odors to focus on the most relevant stimuli, even if they are transient (Ng et al. 2020). Similarly, they are thought to allow particular inputs to be efficiently filtered out at the peripheral level (Zhang et al. 2019; $\mathrm{Ng}$ et al. 2020) with dominant ORNs being selectively favoured, potentially increasing neuronal sensitivity to specific, prioritised chemicals. The importance of valence is highlighted by antagonistic neuronal organisation and it is possible that in some cases, ephaptic inhibition serves to enhance behavioural attraction and suppress repulsion (Ng et al. 2020). In Drosophila, inhibitory mechanisms have been studied at the AL level (Silbering and Galizia 2007) but to date almost all mosquito studies have focused on peripheral mechanisms. Recently, however, a study using Aedes aegypti demonstrated symmetric lateral inhibition between two glomeruli, LC2 and AM2, which respond to the attractive orchid scent nonanal and the neutral orchid scent lilac aldehyde respectively (Lahondère et al. 2019). Inhibitory mechanisms in higher brain areas would be an interesting topic for future research (Pannunzi and Nowotny 2020).

\section{Structure and function of the antennal lobe and subesophageal zone}

The antennal lobe (AL), studied most extensively in Drosophila, acts as an olfactory "relay system", receiving input from olfactory sensory neurons (OSNs) then sending the information to higher brain centres via projection neurons (PNs) (Jefferis et al. 2007). Within the AL, local neurons (LNs) form a connective network between glomeruli. Glomeruli represent functional pieces of olfactory information, which combine to encode a spatial odor map for translation to and then interpretation by higher brain areas. The AL of Anopheles gambiae and Aedes aegypti is innervated by olfactory neurons with cell bodies in the antenna and maxillary palps (Fig. 2) (Riabinina et al. 2016; Raji et al. 2019; Lahondère et al. 2019). In Aedes aegypti, $\mathrm{ORCO}+$ neurons from the stylet also project to the AL (Won Jung et al. 2015). Around half of ORNs innervating the AL in Anopheles gambiae are $\mathrm{ORCO}+$, whilst the remainder are speculated to express IRs (Riabinina et al. 2016). Projection neurons have not been studied in mosquitoes but in Drosophila they target the mushroom body (MB) and the lateral horn (LH) — brain areas that most likely retained their olfactory processing role in mosquitoes. 


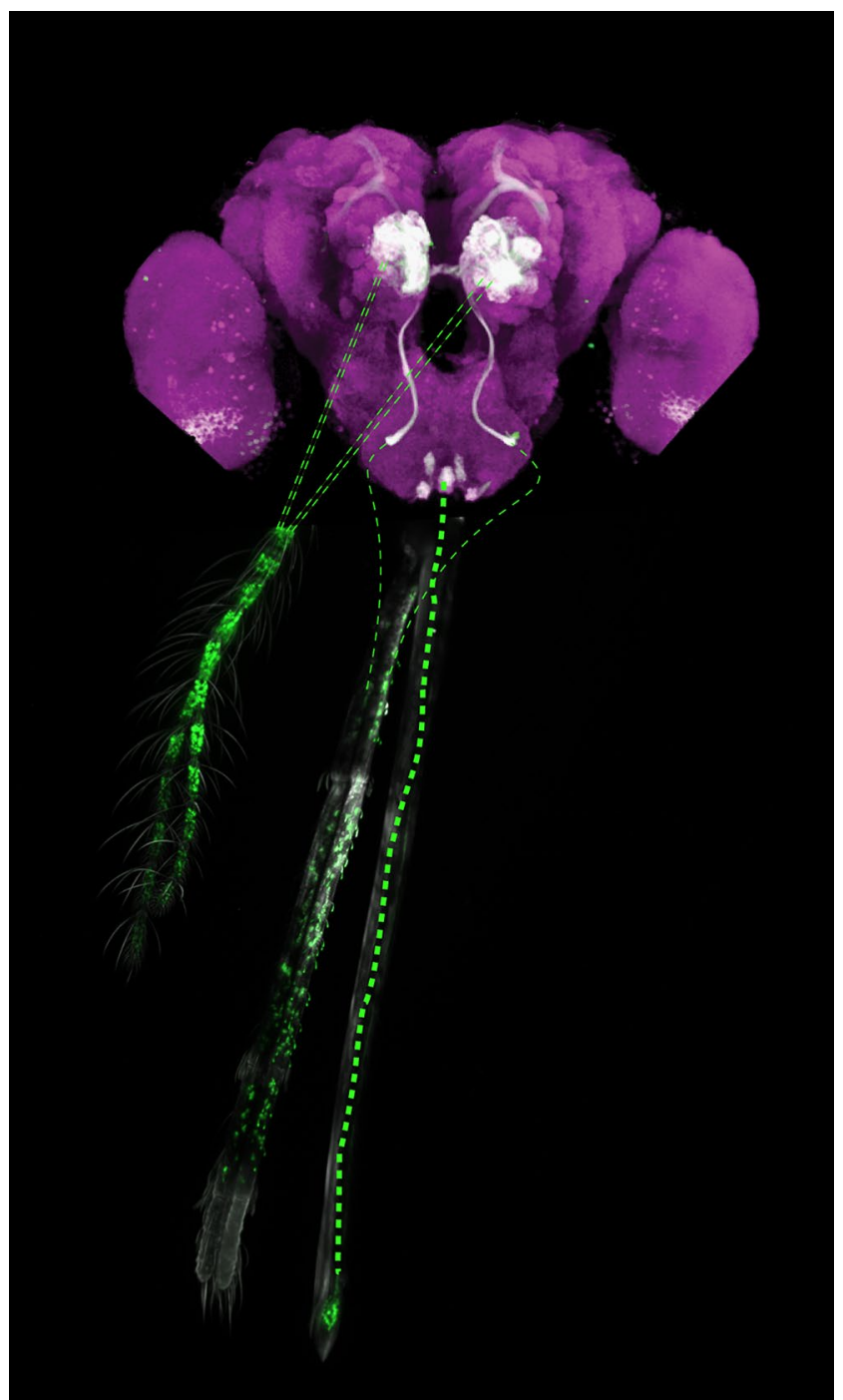

Fig. 2 Olfactory innervations of Anopheles gambiae brain. Axons of olfactory receptor neurons located in the antennae and maxillary palps (thin green dashed lines) innervate specific subsets of glomeruli in the antennal lobe (AL). Axons of olfactory neurons located in the labellum (thick green dotted line) innervate 8 glomeruli-like structures in the suboesophageal zone (SEZ). The image depicts the brain and peripheral olfactory organs of an adult female Anopheles gambiae. Cell bodies of ORCO+ neurons are labelled with GFP

In Drosophila, all ORNs of the same class target a single glomerulus for innervation, thereby producing a mapping system where one glomerulus corresponds with one OR, if a one receptor-one neuron principle is accepted (Komiyama and Luo 2006). In Anopheles gambiae, the number of expressed OR genes is notably greater than the number of ORCO+glomeruli and therefore ORN classes, assuming that each glomerulus is innervated by a single class of ORNs (Riabinina et al. 2016). This observation has three plausible explanations: it may be that ORNs that express different ORs converge on the same glomerulus, or that some ORs are not expressed in olfactory neurons and thus have an alternative function outside of their usual role in olfactory processing, or it may imply some degree of OR co-expression in the same neuron. These explanations are not mutually exclusive.

Such a seemingly disorderly system, where glomeruli have inputs stemming from multiple ORN classes/receptors, may have arisen for several reasons. In some cases, gene duplication could have resulted in co-expressed ORs that respond to very similar odorants (Karner et al. 2015). This could potentially provide increased sensitivity to an odor, in effect amplifying its signal. Alternatively, a one-to-one mapping system may not be required to discriminate between each component of an ecologically relevant mixture. Instead, a neuron may have several receptors that together are broadly tuned to a blend of odors and work collectively to elicit a behavioural response (Karner et al. 2015).

ORNs of Anopheles gambiae also innervate the subesophageal zone (SEZ) (Fig. 2) (Riabinina et al. 2016), the brain region associated in Drosophila with gustatory input and feeding behaviours (Kendroud et al. 2018). Specifically, in Anopheles gambiae ORs from the labella on the proboscis innervate eight SEZ glomeruli. Of these, six appeared strongly and two appeared weakly labelled when investigated using anti-GFP antibody staining (Riabinina et al. 2016). Much of the remaining SEZ area is likely innervated by gustatory and mechanosensory neurons (Ignell et al. 2005). It is well documented that gustatory neurons project to the SEZ via the pharyngeal and labial nerves (Ignell and Hansson 2005) whilst neurons expressing the ppk301 receptor for freshwater detection and blood sensors IR7a/f also project to the SEZ, in this case from the proboscis and pharynx (Matthews et al. 2019; Jové et al. 2020). Based on these findings, it is hypothesised that the SEZ may act as a centre for the integration of olfactory and gustatory information, particularly during blood-feeding (see the "Multisensory integration and host-seeking" section).

The overall structure of the larval brain closely resembles that of the adults, with clearly defined AL, SEZ and optic lobes (Bui et al. 2019 and O.R., personal observation). However, larval ALs are smaller and less developed compared with adults, in line with their simplified olfactory systems; larvae have far fewer sensory neurons, for example Aedes aegypti larvae have 24 ORNs (McIver 1978) compared with 3800 (Zacharuk et al. 1971) in adults. In Anopheles gambiae, larvae have $~ 15$ ORNs and adult females have $\sim 1500$ ORNs (Riabinina et al. 2016). It may be that larvae instead rely on a more heterogeneous selection of IRs and GRs than adults, reflecting their aquatic environment in which gustation as well as olfaction could be utilised in longrange stimulus detection. Bui et al. (2019) hypothesized that there may be particularly strong selective pressure on ORs that are relevant to both larvae and adults. For example, 1-octen3-ol is a decay volatile, which larvae are innately attracted to as detritivores, as well as a host cue, reliably known to activate 
ORNs in adult mosquitoes (Bui et al. 2019). In a behavioural assay, decay volatiles including indole, 2-methylphenol, 3-methylphenol, 4-methylphenol and 4-methylcyclohexanol made up 11 of the 33 chemicals from a broad panel of odors that elicited a significant response from larvae (Xia et al. 2008). Interestingly, larval mushroom bodies are anatomically similar to those of adults, potentially highlighting the importance of olfactory learning in larvae (Lutz et al. 2017).

Whilst at present few studies have investigated higher order neurons and brain organisation in mosquitoes, calcium dyes (Lahondère et al. 2019) and recently developed neurogenetic methods to study mosquito brain activity should help to elucidate these topics. Transgenic strains for live calcium imaging have been developed in Anopheles gambiae and Aedes aegypti, targeting fluorescent calcium indicator GCaMP to all cells (Bui et al. 2019), to all neurons (Jové et al. 2020; Zhao et al. 2020a), or to specific subsets of neurons: ORCO+(Afify et al. 2019), ppk301 (Matthews et al. 2019), IR7a/f and GR4 (Jové et al. 2020). In the adult, live imaging may be conducted in the peripheral (Afify et al. 2019; Jové et al. 2020) or central nervous system (Matthews et al. 2019; Lahondère et al. 2019; Vinauger et al. 2019; Melo et al. 2020). In the larvae, live imaging of brain activity is facilitated by the transparent cuticle of larvae, through which subcutaneous fluorescence can be detected and measured. Additionally, since no surgical cuticle removal is necessary, the individuals may be kept alive sufficiently long to enable repeated testing (Bui et al. 2019). The genetically encoded tools for live imaging are not yet available in other mosquito species, most likely due to the difficulties of generating them in house and the absence of commercial services.

\section{Species differences and sexual dimorphisms in the antennal lobe and subesophageal zone}

Differences in the counted AL glomeruli number have been recorded between Anopheles gambiae, Aedes aegypti and Culex quinquefasciatus (reported in the females for each species to be 67-70, 78-82 and 62 respectively) (Riabinina et al. 2016; Shankar and Mcmeniman 2020; Ye et al. 2020). These figures were obtained using antibody staining with individual glomeruli defined and outlined by hand, a process that inevitably leads to equivocal counts, hence the given ranges. Additionally, tissue deformation during immunostaining procedures may have caused increased individual variability in AL organisation, providing a further source of ambiguity.

The numbers of AL glomeruli in Culex quinquefasciatus mosquitoes are strongly sexually dimorphic, with 44 glomeruli in males and 62 glomeruli in females. However, similar glomeruli numbers are seen in males and females of Anopheles gambiae (67-68 in males, 67-70 in females) and Aedes aegypti (75-79 in males, 78-82 in females). Total AL volume is larger in females: 1.9 times greater in Anopheles gambiae, 1.4 times greater in Aedes aegypti and
3.1 times greater in Culex quinquefasciatus. This is likely because females have a far greater number of ORNs than males, about twice the number in Anopheles gambiae, meaning each glomerulus is innervated by more ORNs and is therefore larger. Supporting this, nc82 antibody staining is more intense and clearly segmented in females (Riabinina et al. 2016). These differences reflect the additional olfactory tasks required only of females, particularly relating to oviposition and host-seeking. For example, decay volatiles are not obviously useful to a male mosquito; however, they are specifically important for females in determining an ideal site for oviposition, since the environment's microbial composition affects offspring fitness (Lutz et al. 2017). Sexual dimorphism between the relative volumes of glomeruli has also been identified for two specific glomeruli, AD1 and VC1, in Aedes aegypti, which may similarly be linked to these behaviours (Shankar and Mcmeniman 2020). In contrast to the AL, the SEZ appears to demonstrate little sexual dimorphism; however, Anopheles gambiae is the only species for which this has been investigated (Riabinina et al. 2016).

\section{Multisensory integration and host-seeking}

Mosquitoes integrate olfactory signals with other sensory inputs-namely temperature, humidity, mechanosensory and visual information-an ability vital for host-seeking, danger avoidance, mate finding and the location of suitable oviposition sites (Potter 2014; McMeniman et al. 2014; Breugel et al. 2015; Vinauger et al. 2019). Female mosquitoes of many species rely on blood-feeding to gain vital nutrients for egg development, whilst their metabolic demands are primarily satisfied through nectar feeding. Host detection involves sensing and integrating three main cues: $\mathrm{CO}_{2}$, host body odour and heat, though moisture detection and visual cues are also involved. $\mathrm{CO}_{2}$ detection is accomplished at the receptor level by three GRs (McMeniman et al. 2014; Xu et al. 2020; Kumar et al. 2020; Liu et al. 2020), while the bouquet of human body odor requires information from a range of ORs and IRs. The topic of heat detection and its underlying mechanisms has been the subject of recent research (Corfas and Vosshall 2015; Greppi et al. 2020), with a study using Anopheles gambiae finding that the IR21a receptor is highly involved in detecting cooling. With this proposed IR acting as a mediator, the apparent seeking of heat may in fact be an aversion to cool temperatures (Greppi et al. 2020).

In general, at least two of the three primary cues listed above must be simultaneously detected to evoke a hostseeking response, an advantageous principle in complex environments where one cue alone may not be a sufficiently reliable indicator of, in the case of Aedes aegypti, a human host (McMeniman et al. 2014). However, at close range 
fewer cues may be sufficient. $\mathrm{CO}_{2}$ is thought to initiate host seeking at the longest range (around $10 \mathrm{~m}$ ) whilst odor (Bernier et al. 2007; Robinson et al. 2018) and visual (Breugel et al. 2015) cues are involved at a distance of up to $2 \mathrm{~m}$ and heat is particularly important at a close range of less than $15 \mathrm{~cm}$ (Cardé 2015), at which point the temperature difference between a human arm and ambient temperature falls below the $0.2{ }^{\circ} \mathrm{C}$ detection threshold for Aedes aegypti (Davis and Sokolove 1975). In such circumstances, heat alone may be a sufficient cue to attract mosquitoes and initiate landing; it was found that female mosquitoes reliably $(p=0.024)$ choose the heat source at $34{ }^{\circ} \mathrm{C}$ (host range) over one at $25{ }^{\circ} \mathrm{C}$ (ambient) in a $\mathrm{Y}$ maze olfactometer with no other host cues present (Zermoglio et al. 2017). Although this experiment placed the heat sources as far away as $37 \mathrm{~cm}$, it is likely that heat does not dissipate as quickly within the confines of a Y maze compared with open air.

Once the host has been located, ORs housed in the stylet may be used to find the best site at which to pierce the skin, in order to precisely locate blood vessels without alerting the host (Won Jung et al. 2015). When AaOr8 and AaOr49 receptors, usually expressed in the stylet of Aedes aegypti, were downregulated, the mosquitoes demonstrated significantly higher levels of stylet probing and longer engorgement times, implicating these ORs in bloodseeking processes. The authors also identified two olfactory glomeruli in the AL that are innervated by stylet ORNs, further indicating olfactory involvement (Won Jung et al. 2015). Six stylet IR neurons are also involved in tasting blood via IR7a/f receptors (Jové et al. 2020).

Visual-olfactory integration has an important role in host detection in Aedes aegypti (Breugel et al. 2015). Presentation of the attractive cue odor $\mathrm{CO}_{2}$ alongside the visual stimulus of horizontal moving bars led to an increase in bar-tracking fidelity compared with a clean air control (Vinauger et al. 2019). In other words, $\mathrm{CO}_{2}$ presentation seems to modulate visual responses, making the mosquitoes particularly drawn to visual features. Further experiments looked to identify the neural basis of this phenomenon. Using Aedes aegypti, regions of interest (ROIs) were identified in the lobula, a neuropil in the optic lobe, corresponding to areas with high GCaMP6s (a calcium indicator) expression. When mosquitoes were presented with $\mathrm{CO}_{2}$ preceding the visual stimulus, fluorescent responses were significantly higher in 14 out of 59 ROIs (though lower in 2), suggesting a positive modulatory effect. However, visual-olfactory modulation is thought to be asymmetric, in that prior presentation of a visual stimulus does not alter olfactory signals (Vinauger et al. 2019).

Distinguishing human odor from that of non-human animals is a crucial ability for many anthropophilic vector species. Recently, a glomerulus activated exclusively by human odours was identified in Aedes aegypti (the "human-sensitive" glomerulus). This glomerulus is specifically tuned to detect long-chain aldehydes, a high concentration of which characterises human odor. It is proposed that in conjunction with a broadly tuned "universal" glomerulus, mosquitoes are able to gain information about the relative concentration of long-chain aldehydes and therefore reliably determine whether a given odor is from a human (Zhao et al. 2020b).

\section{Conclusions and future perspectives}

There has been a recent boom in knowledge about mosquito olfactory systems but there is still much to learn. For instance, the OR/IR repertoire of many species is completely unknown. Particularly interesting are species that do not use vertebrates as hosts, such as Uranotaenia sapphirina, which feeds on annelid worms (Reeves et al. 2018) and Malaya mosquitoes that feed via trophallaxis from ants (Miyagi 1981). It would be interesting to see what chemical cues these species use to find their hosts and whether they have novel receptors to detect these cues.

Another interesting avenue of research is to examine the olfactory repertoires and receptors of larvae with different ecologies. For example, Anopheles gambiae or Aedes aegypti larvae filter feed on biofilms and bacteria, while larvae of Toxorhynchites sp. are predatory and may be attracted by chemical cues produced by their prey larvae. While most species of mosquito develop in freshwater, there are some that develop in water with higher salinity, e.g., Anopheles aquasalis (Grillet 2000) and Aedes togoi (Trimble and Wellington 1979). Different salinity implies different bacterial communities in each of these settings, which may produce different metabolites, as well as different chemical solubilities and thus may be followed by a co-evolving repertoire of olfactory receptors in the larvae.

Most of the past and recent work has focused on studies of the peripheral olfactory systems of mosquitoes. The next step is to extend the existing methods of recording neuronal responses to specific neuronal subpopulations in higher order brain centres to provide insights into olfactory and multisensory coding.

Future research will require three strands of groundwork. First, we need to learn about mosquito behaviour in the field and their ecologically relevant cues before olfactory or multisensory responses to these cues may be investigated. Second, we will need to develop new behavioural assays that realistically mimic field situations for mosquitoes. Third, molecular and genetic tools will need to be implemented in new species, which in turn will require established lab colonies, commercial services for transgenesis and suitable stock centres. Luckily, with over 3550 extant mosquito species, we are unlikely to run out of exciting new findings any time soon. 


\section{Conflict of interest}

The authors declare that they have no conflict of interest.

\section{Ethical approval}

No animals or human subjects were involved in this research and thus no ethical approval and informed consent was necessary.

Acknowledgements We thank Albert Cardona and Lisa Baik for help with finding images for illustrations, and Courtney Akitake for the image of the antennae, maxillary palps and proboscis of an Orco-GFP mosquito used in Fig. 2. We also thank Don Loarie, Katja Schulz, Wendy Moore, Zygy, skitterbug, Arturo Santos, Even Dankowicz, Alan Manson, Steve Kerr, James Gathany, Judy Gallagher, and Maycon Neves for the images used in Fig. 1.

Funding This work was supported by the Wellcome Seed Award (217440/Z/19/Z to OR) and Durham Department of Biosciences Summer Studentship (to CRW).

Open Access This article is licensed under a Creative Commons Attribution 4.0 International License, which permits use, sharing, adaptation, distribution and reproduction in any medium or format, as long as you give appropriate credit to the original author(s) and the source, provide a link to the Creative Commons licence, and indicate if changes were made. The images or other third party material in this article are included in the article's Creative Commons licence, unless indicated otherwise in a credit line to the material. If material is not included in the article's Creative Commons licence and your intended use is not permitted by statutory regulation or exceeds the permitted use, you will need to obtain permission directly from the copyright holder. To view a copy of this licence, visit http://creativecommons.org/licenses/by/4.0/.

\section{References}

Afify A, Betz JF, Riabinina O et al (2019) Commonly used insect repellents hide human odors from anopheles mosquitoes. Curr Biol 29:3669-3680.e5. https://doi.org/10.1016/j.cub.2019.09.007

Athrey G, Cosme LV, Popkin-Hall Z et al (2017) Chemosensory gene expression in olfactory organs of the anthropophilic Anopheles coluzzii and zoophilic Anopheles quadriannulatus. BMC Genomics 18:751. https://doi.org/10.1186/s12864-017-4122-7

Balkew M, Mumba P, Dengela D et al (2020) Geographical distribution of Anopheles stephensi in eastern Ethiopia. Parasit Vectors 13:18. https://doi.org/10.1186/s13071-020-3904-y

Ben-Shahar Y, Lu B, Collier DM et al (2010) The Drosophila gene CheB42a is a novel modifier of Deg/ENaC channel function. PLoS ONE 5:9395. https://doi.org/10.1371/journal.pone.0009395

Benton R, Vannice KS, Gomez-Diaz C, Vosshall LB (2009) Variant ionotropic glutamate receptors as chemosensory receptors in Drosophila. Cell 136:149-162. https://doi.org/10.1016/j. cell.2008.12.001

Bernier UR, Kline DL, Allan SA, Barnard DR (2007) Laboratory comparison of Aedes aegypti attraction to human odors and to synthetic human odor compounds and blends. J Am Mosq Control Assoc. 23(3):288-293. https://doi.org/10.2987/8756971X(2007)23[288:LCOAAA]2.0.CO;2
Biessmann H, Andronopoulou E, Biessmann MR et al (2010) The Anopheles gambiae Odorant Binding Protein 1 (AgamOBP1) mediates indole recognition in the antennae of female mosquitoes. PLoS ONE 5:9471. https://doi.org/10.1371/journal.pone.0009471

Bohbot J, Pitts RJ, Kwon H-WW et al (2007) Molecular characterization of the Aedes aegypti odorant receptor gene family. Insect Mol Biol. https://doi.org/10.1111/j.1365-2583.2007.00748.x

Bohbot JD, Dickens JC (2009) Characterization of an enantioselective odorant receptor in the yellow fever mosquito Aedes aegypti. PLoS ONE 4. https://doi.org/10.1371/journal.pone.0007032

Bohbot JD, Jones PL, Wang G et al (2011) Conservation of indole responsive odorant receptors in mosquitoes reveals an ancient olfactory trait. Chem Senses 36:149-160. https://doi.org/10.1093/ chemse/bjq105

Bohbot JD, Sparks JT, Dickens JC (2014) The maxillary palp of Aedes aegypti, a model of multisensory integration. Insect Biochem Mol Biol 48:29-39. https://doi.org/10.1016/j.ibmb.2014.02.007

Bradshaw WE, Burkhart J, Colbourne JK et al (2018) Evolutionary transition from blood feeding to obligate nonbiting in a mosquito. Proc Natl Acad Sci U S A 115:1009-1014. https://doi.org/10.1073/ pnas. 1717502115

Bui M, Shyong J, Lutz EK et al (2019) Live calcium imaging of Aedes aegypti neuronal tissues reveals differential importance of chemosensory systems for life-history-specific foraging strategies. BMC Neurosci 20:27. https://doi.org/10.1186/s12868-019-0511-y

Butterwick JA, del Mármol J, Kim KH et al (2018) Cryo-EM structure of the insect olfactory receptor Orco. Nature 560:447452. https://doi.org/10.1038/s41586-018-0420-8

Cali K, Persaud KC (2020) Modification of an Anopheles gambiae odorant binding protein to create an array of chemical sensors for detection of drugs. Sci Rep 10:1-13. https://doi.org/10.1038/ s41598-020-60824-7

Cardé RT (2015) Multi-cue integration: how female mosquitoes locate a human host. Curr Biol 25:R793-R795. https://doi.org/10.1016/j. cub.2015.07.057

Carey AF, Wang G, Su CY et al (2010) Odorant reception in the malaria mosquito Anopheles gambiae. Nature 464:66-71. https://doi. org/10.1038/nature08834

Chen XG, Jiang X, Gu J et al (2015) Genome sequence of the Asian tiger mosquito, aedes albopictus, reveals insights into its biology, genetics, and evolution. Proc Natl Acad Sci U S A 112:E5907E5915. https://doi.org/10.1073/pnas.1516410112

Choo YM, Buss GK, Tan K, Leal WS (2015) Multitasking roles of mosquito labrum in oviposition and blood feeding. Front Physiol 6:306. https://doi.org/10.3389/fphys.2015.00306

Coetzee M, Hunt RH, Wilkerson R et al (2013) Anopheles coluzzii and Anopheles amharicus, new members of the Anopheles gambiae complex. Zootaxa 3619:246-274

Collins LE, Blackwell A (2000) The biology of Toxorhynchites mosquitoes and their potential as biocontrol agents. Biocontrol News and Information 21(4):105N-116N

Cook JI, Majeed S, Ignell R et al (2011) Enantiomeric selectivity in behavioural and electrophysiological responses of Aedes aegypti and Culex quinquefasciatus mosquitoes. Bull Entomol Res 101:541-550. https://doi.org/10.1017/S0007485311000162

Corfas RA, Vosshall LB (2015) The cation channel TRPA1 tunes mosquito thermotaxis to host temperatures. Elife 4:1-16. https:// doi.org/10.7554/eLife.11750.001

Couto A, Alenius M, Dickson BJ (2005) Molecular, anatomical, and functional organization of the Drosophila olfactory system. Curr Biol 15:1535-1547. https://doi.org/10.1016/j.cub.2005.07.034

De Das T, Thomas T, Verma S et al (2018) A synergistic transcriptional regulation of olfactory genes drives blood-feeding associated complex behavioral responses in the mosquito anopheles culicifacies. Front Physiol 9:577. https://doi.org/10.3389/fphys.2018.00577 
Davis EE, Sokolove PG (1975) Temperature responses of antennal receptors of the mosquito, Aedes aegypti. J Comp Physiol 96:223236. https://doi.org/10.1007/BF00612696

Degennaro M, McBride CS, Seeholzer L et al (2013) Orco mutant mosquitoes lose strong preference for humans and are not repelled by volatile DEET. Nature 498:487-491. https://doi.org/10.1038/ nature 12206

Dekel A, Pitts RJ, Yakir E, Bohbot JD (2016) Evolutionarily conserved odorant receptor function questions ecological context of octenol role in mosquitoes. Sci Rep 6 https://doi.org/10.1038/srep37330

Dekel A, Yakir E, Bohbot JD (2019a) The sulcatone receptor of the strict nectar-feeding mosquito Toxorhynchites amboinensis. Insect Biochem Mol Biol 111 https://doi.org/10.1016/j.ibmb.2019.05.009

Dekel A, Yakir E, Bohbot JD (2019b) The evolutionarily conserved indolergic receptors of the non-hematophagous elephant mosquito Toxorhynchites amboinensis. Insect Biochem Mol Biol 110:45-51. https://doi.org/10.1016/j.ibmb.2019.04.015

Deng Y, Yan H, Gu J et al (2013) Molecular and functional characterization of odorant-binding protein genes in an invasive vector mosquito. Aedes albopictus PLoS One 8:e68836. https:// doi.org/10.1371/journal.pone.0068836

Dobritsa AA, Der Goes V, Van Naters W, Warr CG et al (2003) Integrating the molecular and cellular basis of odor coding in the Drosophila antenna. Neuron 37:827-841. https://doi.org/10.1016/S08966273(03)00094-1

Fandino RA, Haverkamp A, Bisch-Knaden S et al (2019) Mutagenesis of odorant coreceptor Orco fully disrupts foraging but not oviposition behaviors in the hawkmoth Manduca sexta. Proc Natl Acad Sci 201902089 https://doi.org/10.1073/PNAS.1902089116

Fishilevich E, Domingos AI, Asahina K et al (2005) Chemotaxis behavior mediated by single larval olfactory neurons in Drosophila. Curr Biol 15:2086-2096. https://doi.org/10.1016/j. cub.2005.11.016

Fox AN, Pitts RJ, Zwiebel LJ (2002) A cluster of candidate odorant receptors from the malaria vector mosquito, Anopheles gambiae. Chem Senses 27:453-459. https://doi.org/10.1093/chemse/ 27.5.453

Futami K, Iwashita H, Higa Y et al (2020) Geographical distribution of Aedes aegypti\&nbsp; and Aedes aegypti formosus (Diptera: Culicidae) in Kenya and environmental factors related to their relative abundance. J Med Entomol 57:772-779. https://doi. org/10.1093/jme/tjz233

Ghaninia M, Ignell R, Hansson BS (2007) Functional classification and central nervous projections of olfactory receptor neurons housed in antennal trichoid sensilla of female yellow fever mosquitoes, Aedes aegypti. Eur J Neurosci 26:1611-1623. https://doi.org/10. 1111/j.1460-9568.2007.05786.x

Ghaninia M, Larsson M, Hansson BS, Ignell R (2008) Natural odor ligands for olfactory receptor neurons of the female mosquito Aedes aegypti: use of gas chromatography-linked single sensillum recordings. J Exp Biol 211:3020-3027. https://doi. org/10.1242/jeb.016360

Goldman AL, van der Goes van Naters W, Lessing D et al (2005) Coexpression of two functional odor receptors in one neuron. Neuron 45:661-666. https://doi.org/10.1016/j.neuron.2005.01.025

Gomulski LM, Manni M, Carraretto D et al (2020) Transcriptional variation of sensory-related genes in natural populations of Aedes albopictus BMC. Genomics 21 https://doi.org/10.1186/s12864020-06956-6

Greppi C, Laursen WJ, Budelli G et al (2020) Mosquito heat seeking is driven by an ancestral cooling receptor. Science 367:681-684. https://doi.org/10.1126/science.aay 9847

Grillet ME (2000) Factors associated with distribution of Anopheles aquasalis and Anopheles oswal (Diptera: Culicidae) in a malarious area. Northeastern Venezuela. J Med Entomol. 37(2):231-238. https://doi.org/10.1603/0022-2585-37.2.231
Hall DR, Beevor PS, Cork A et al (1984) 1-Octen-3-ol. A potent olfactory stimulant and attractant for tsetse isolated from cattle odours. Int J Trop Insect Sci 5:335-339. https://doi.org/10.1017/ s1742758400008626

Hao YJ, Zou YL, Ding YR et al (2017) Complete mitochondrial genomes of Anopheles stephensi and An. dirus and comparative evolutionary mitochondriomics of 50 mosquitoes. Sci Rep 7:113. https://doi.org/10.1038/s41598-017-07977-0

Harbach R (2018) Culicipedia: species-group, genus-group and familygroup names in Culicidae (Diptera). CABI

He X, He ZB, Zhang YJ et al (2016) Genome-wide identification and characterization of odorant-binding protein (OBP) genes in the malaria vector Anopheles sinensis (Diptera: Culicidae). Insect Sci 23:366-376. https://doi.org/10.1111/1744-7917.12333

Heard SB (1994) Imperfect oviposition decisions by the pitcher plant mosquito (Wyeomyia smithii). Evol Ecol 8:493-502. https://doi. org/10.1007/BF01238254

Hill CA, Fox AN, Pitts RJ et al (2002) G protein-coupled receptors in Anopheles gambiae. Science (80) 298:176-178. https://doi. org/10.1126/science.1076196

Huff RM, Jason Pitts R (2019) An odorant receptor from Anopheles gambiae that demonstrates enantioselectivity to the plant volatile, linalool. PLoS ONE 14 https://doi.org/10.1371/journal. pone. 0225637

Ignell R, Dekker T, Ghaninia M, Hansson BS (2005) Neuronal architecture of the mosquito deutocerebrum. J Comp Neurol 493:207-240. https://doi.org/10.1002/cne.20800

Ignell R, Hansson BS (2005) Projection patterns of gustatory neurons in the suboesophageal ganglion and tritocerebrum of mosquitoes. J Comp Neurol 492:214-233. https://doi.org/10.1002/cne.20691

Ishida Y, Cornel AJ, Leal WS (2002) Identification and cloning of a female antenna-specific odorant-binding protein in the mosquito Culex quinquefasciatus. J Chem Ecol 28:1-6

Jefferis GSXE, Potter CJ, Chan AM et al (2007) Comprehensive maps of Drosophila higher olfactory centers: spatially segregated fruit and pheromone representation. Cell 128:1187-1203. https://doi. org/10.1016/j.cell.2007.01.040

Jové V, Gong Z, Hol FJH et al (2020) The taste of blood in mosquitoes. bioRxiv 2020.02.27.954206. https://doi.org/10.1101/2020.02.27.954206

Karner T, Kellner I, Schultze A et al (2015) Co-expression of six tightly clustered odorant receptor genes in the antenna of the malaria mosquito Anopheles gambiae. Front Ecol Evol 3:1-8. https://doi. org/10.3389/fevo.2015.00026

Keesey IW, Grabe V, Gruber L et al (2019) Inverse resource allocation between vision and olfaction across the genus Drosophila. Nat Commun 10:1-16. https://doi.org/10.1038/s41467-019-09087-z

Kendroud S, Bohra AA, Kuert PA et al (2018) Structure and development of the subesophageal zone of the Drosophila brain. II Sensory compartments J Comp Neurol 526:33-58. https://doi.org/10.1002/ cne. 24316

Khalifa RMA, El-Nady NA, Ahmed AM et al (2013) Comparative study of the sensilla on antenna and maxillary palps of five culicine mosquitoes in Sohag governorate. Egypt Soc Parasitol 43(2):481-491. https://doi.org/10.12816/0006405

Knudsen JT, Tollsten L, Bergström LG (1993) Floral scents-a checklist of volatile compounds isolated by head-space techniques. Phytochemistry 33:253-280

Komiyama T, Luo L (2006) Development of wiring specificity in the olfactory system. Curr Opin Neurobiol 16:67-73. https://doi. org/10.1016/j.conb.2005.12.002.

Kumar A, Tauxe GM, Perry S et al (2020) Contributions of the conserved insect carbon dioxide receptor subunits to odor detection. Cell Rep 31:107510. https://doi.org/10.1016/j.celrep. 2020.03.074

Kwon HW, Lu T, Rützler M, Zwiebel LJ (2006) Olfactory response in a gustatory organ of the malaria vector mosquito Anopheles 
gambiae. Proc Natl Acad Sci U S A 103:13526-13531. https:// doi.org/10.1073/pnas.0601107103

Lahondère C, Vinauger CC, Okubo RP et al (2019) The olfactory basis of orchid pollination by mosquitoes. PNAS 117:708-716. https:// doi.org/10.1073/pnas.1910589117

Lapshin DN (2012) Mosquito bioacoustics: auditory processing in Culex pipiens pipiens $\mathrm{L}$. Males (Diptera, Culicidae) during flight simulation. Entomol Rev 92:605-621. https://doi.org/10.1134/ S0013873812060024

Larter NK, Sun JS, Carlson JR (2016) Organization and function of Drosophila odorant binding proteins. Elife $5 \mathrm{https}: / /$ doi. org/10.7554/eLife. 20242

Leal WS (2013) Odorant reception in insects: roles of receptors, binding proteins, and degrading enzymes. Annu Rev Entomol 58:373391. https://doi.org/10.1146/annurev-ento-120811-153635

Leal WS, Choo YM, Xu P et al (2013) Differential expression of olfactory genes in the southern house mosquito and insights into unique odorant receptor gene isoforms. Proc Natl Acad Sci U S A 110:18704-18709. https://doi.org/10.1073/pnas.1316059110

Li ZX, Pickett JA, Field LM, Zhou JJ (2005) Identification and expression of odorant-binding proteins of the malaria-carrying mosquitoes Anopheles gambiae and Anopheles arabiensis. Arch Insect Biochem Physiol 58:175-189. https://doi.org/10.1002/arch.20047

Lin H, Mann KJ, Starostina E et al (2005) A Drosophila DEG/ $\mathrm{ENaC}$ channel subunit is required for male response to female pheromones. Proc Natl Acad Sci U S A 102:12831-12836. https:// doi.org/10.1073/pnas.0506420102

Liu C, Pitts RJ, Bohbot JD et al (2010) Distinct olfactory signaling mechanisms in the malaria vector mosquito Anopheles gambiae. PLoS Biol 8:e1000467. https://doi.org/10.1371/journal. pbio. 1000467

Liu F, Ye Z, Baker A et al (2020) Gene editing reveals obligate and modulatory components of the $\mathrm{CO}_{2}$ receptor complex in the malaria vector mosquito Anopheles coluzzii. Insect Biochem Mol Biol 103470 https://doi.org/10.1016/j.ibmb.2020.103470

Lodovichi C, Belluscio L (2012) Odorant receptors in the formation of the olfactory bulb circuitry organization of the mammalian olfactory system. Physiology 27:200-212. https://doi. org/10.1152/physiol.00015.2012

Lombardo F, Salvemini M, Fiorillo C et al (2017) Deciphering the olfactory repertoire of the tiger mosquito Aedes albopictus. BMC Genomics 18:1-23. https://doi.org/10.1186/s12864-017-4144-1

Lu T, Qiu YT, Wang G et al (2007) Odor coding in the maxillary palp of the malaria vector mosquito Anopheles gambiae. Curr Biol 17:1533-1544. https://doi.org/10.1016/j.cub.2007.07.062

Lutz EK, Ha KT, Riffell JA (2020) Distinct navigation behaviors in Aedes, Anopheles, and Culex mosquito larvae. J Exp Biol 223:jeb.221218. https://doi.org/10.1242/jeb.221218

Lutz EK, Lahondère C, Vinauger C, Riffell JA (2017) Olfactory learning and chemical ecology of olfaction in disease vector mosquitoes: a life history perspective. Curr Opin Insect Sci 20:75-83. https:// doi.org/10.1016/j.cois.2017.03.002

Maguire SE, Afify A, Goff LA et al (2020) A feedback mechanism regulates odorant receptor expression in the malaria mosquito. Anopheles gambiae bioRxiv 07(23):218586. https://doi. org/10.1101/2020.07.23.218586

Manoharan M, Chong MNF, Vaïtinadapoulé A et al (2013) Comparative genomics of odorant binding proteins in Anopheles gambiae, Aedes aegypti, and Culex quinquefasciatus. Genome Biol Evol 5:163-180. https://doi.org/10.1093/gbe/evs131

Matthews BJ, McBride CS, DeGennaro M et al (2016) The neurotranscriptome of the Aedes aegypti mosquito. BMC Genomics 17:32. https://doi.org/10.1186/s12864-015-2239-0

Matthews BJ, Younger MA, Vosshall LB (2019) The ion channel ppk301 controls freshwater egg-laying in the mosquito Aedes aegypti. Elife 8 https://doi.org/10.7554/eLife.43963
McBride CS, Baier F, Omondi AB et al (2014) Evolution of mosquito preference for humans linked to an odorant receptor. Nature 515:222-227. https://doi.org/10.1038/nature13964

McIver S (1971) Comparative studies on the sense organs on the antennae and maxillary palps of selected male culicine mosquitoes. Can J Zool 49:235-239. https://doi.org/10.1139/z71-033

McIver S (1978) Structure of sensilla trichodea of female Aedes aegypti with comments on innervation of antennal sensilla. J Insect Physiol 24:383-390. https://doi.org/10.1016/0022-1910(78)90079-3

McIver S, Hudson A (1972) Sensilla on the antennae and palps of selected Wyeomyia mosquitoes. J Med Entomol 9:337-345

McMeniman CJ, Corfas RA, Matthews BJ et al (2014) Multimodal integration of carbon dioxide and other sensory cues drives mosquito attraction to humans. Cell 156:1060-1071. https://doi. org/10.1016/j.cell.2013.12.044

Melo ACA, Rützler M, Pitts RJ, Zwiebel LJ (2004) Identification of a chemosensory receptor from the yellow fever mosquito, Aedes aegypti, that is highly conserved and expressed in olfactory and gustatory organs. Chem Senses 29:403-410. https://doi. org/10.1093/chemse/bjh041

Melo N, Wolff GH, Costa-da-Silva AL et al (2020) Geosmin attracts Aedes aegypti mosquitoes to oviposition sites. Curr Biol 30:127134.e5. https://doi.org/10.1016/j.cub.2019.11.002

Missbach C, Dweck HKM, Vogel H et al (2014) Evolution of insect olfactory receptors. Elife 2014 https://doi.org/10.7554/eLife.02115

Miyagi I (1981) Malaya leei (Wharton) feeding on ants in Papua New Guinea : Diptera : Culicidae. Med Entomol Zool 32:332-333. https://doi.org/10.7601/mez.32.332

Mozūraitis R, Hajkazemian M, Zawada JW et al (2020) Male swarming aggregation pheromones increase female attraction and mating success among multiple African malaria vector mosquito species. Nat Ecol Evol 1-7. https://doi.org/10.1038/s41559-020-1264-9

Murlis J, Elkinton JS, Cardé RT (1992) Odor plumes and how insects use them. Annu Rev Entomol 37:505-532. https://doi. org/10.1146/annurev.en.37.010192.002445

Neafsey DE, Waterhouse RM, Abai MR, et al (2015) Highly evolvable malaria vectors: The genomes of 16 Anopheles mosquitoes. Science (80- ) 347. https://doi.org/10.1126/science.1258522

Ng R, Wu S, Su C (2020) Neuronal compartmentalization: a means to integrate sensory input at the earliest stage of information processing? BioEssays 42:2000026. https://doi.org/10.1002/ bies. 202000026

Nikbakhtzadeh MR, Buss GK, Leal WS (2016) Toxic effect of blood feeding in male mosquitoes. Front Physiol 7:4. https://doi. org/10.3389/fphys.2016.00004

Nikbakhtzadeh MR, Terbot JW, Otienoburu PE, Foster WA (2014) Olfactory basis of floral preference of the malaria vector Anopheles gambiae (Diptera: Culicidae) among common African plants. J Vector Ecol. 39(2): 372-383. https://doi.org/10.1111/jvec.12113

Nikonov AA, Leal WS (2002) Peripheral coding of sex pheromone and a behavioral antagonist in the Japanese beetle, Popillia japonica. J Chem Ecol 28:1075-1089. https://doi.org/10.1023/A:1015274104626

O’Meara GF (1985) Gonotrophic interactions in mosquitoes: kicking the blood-feeding habit. Florida Entomol 68:122. https://doi. org/10.2307/3494335

Pannunzi M, Nowotny T (2020) Non-synaptic interactions between olfactory receptor neurons, a possible key feature of odor processing in insects. bioRxiv. https://doi.org/10.1101/2020.07.23.217216

Park SK, Mann KJ, Lin H, et al (2006) A Drosophila protein specific to pheromone-sensing gustatory hairs delays males' copulation attempts. Curr Biol 16:1154-1159. https://doi.org/10.1016/j. cub.2006.04.028

Peach DAH, Gries R, Young N, et al (2019) Attraction of female Aedes aegypti (L.) to aphid honeydew. Insects 10: https://doi. org/10.3390/insects10020043 
Pelletier J, Guidolin A, Syed Z et al (2010) Knockdown of a mosquito odorant-binding protein involved in the sensitive detection of oviposition attractants. J Chem Ecol 36:245-248. https://doi. org/10.1007/s10886-010-9762-x

Pelosi P, Iovinella I, Zhu J et al (2018) Beyond chemoreception: diverse tasks of soluble olfactory proteins in insects. Biol Rev 93:184-200. https://doi.org/10.1111/brv.12339

Pitts RJ, Derryberry SL, Zhang Z, Zwiebel LJ (2017) Variant ionotropic receptors in the malaria vector mosquito Anopheles gambiae tuned to amines and carboxylic acids. Sci Rep 7:1-11. https://doi.org/10.1038/srep40297

Pitts RJ, Fox AN, Zwiebeil LJ (2004) A highly conserved candidate chemoreceptor expressed in both olfactory and gustatory tissues in the malaria vector Anopheles gambiae. Proc Natl Acad Sci U S A 101:5058-5063. https://doi.org/10.1073/pnas.0308146101

Pitts RJ, Rinker DC, Jones PL et al (2011) Transcriptome profiling of chemosensory appendages in the malaria vector Anopheles gambiae reveals tissue- and sex-specific signatures of odor coding. BMC Genomics 12:271. https://doi.org/10.1186/1471-2164-12-271

Ponnusamy L, Xu N, Nojima S, et al (2008) Identification of bacteria and bacteria-associated chemical cues that mediate oviposition site preferences by Aedes aegypti. PNAS 105:9262-9267. https://doi. org/10.1073/pnas.0802505105

Potter CJ (2014) Stop the biting: targeting a mosquito's sense of smell. Cell 156:878-881. https://doi.org/10.1016/j.cell.2014.02.003

Qiu YT, van Loon JJA, Takken W et al (2006) Olfactory coding in antennal neurons of the malaria mosquito, Anopheles gambiae. Chem Senses 31:845-863. https://doi.org/10.1093/chemse/bj1027

Raji JI, Melo N, Castillo JS et al (2019) Aedes aegypti mosquitoes detect acidic volatiles found in human odor using the IR8a pathway. Curr Biol 1253-1262.e7 https://doi.org/10.1016/j.cub.2019.02.045

Rattanarithikul R, Harbach RE, Harrison BA et al (2007) Illustrated keys to the mosquitoes of Thailand V. Genera Orthopodomyia, Kimia, Malaya, Topomyia, Tripteroides, and Toxorhynchites. Southeast Asian J Trop Med Public Heal 38:1-65

Reeves LE, Holderman CJ, Blosser EM et al (2018) Identification of Uranotaenia sapphirina as a specialist of annelids broadens known mosquito host use patterns. Commun Biol 1 https://doi.org/10.1038/ s42003-018-0096-5

Riabinina O, Task D, Marr E et al (2016) Organization of olfactory centres in the malaria mosquito Anopheles gambiae. Nat Commun $7 \mathrm{https} / /$ doi.org/10.1038/ncomms 13010

Robertson HM, Kent LB (2009) Evolution of the gene lineage encoding the carbon dioxide receptor in insects. J Insect Sci 9:19. https://doi. org/10.1673/031.009.1901

Robinson A, Busula AO, Voets MA et al (2018) Plasmodium-associated changes in human odor attract mosquitoes. Int Cent Insect Physiol Ecol. https://doi.org/10.1073/pnas.1721610115

Rose NH, Sylla M, Badolo A et al (2020) Climate and urbanization drive mosquito preference for humans. Curr Biol $30 \mathrm{https} / / / \mathrm{doi}$. org/10.1016/j.cub.2020.06.092

Ruel DM, Yakir E, Bohbot JD (2019) Supersensitive odorant receptor underscores pleiotropic roles of Indoles in mosquito ecology. Front Cell Neurosci 12 https://doi.org/10.3389/fncel.2018.00533

Ryba AR, McKenzie SK, Olivos-Cisneros L et al (2020) Comparative development of the ant chemosensory system. Curr Biol 30:32233230.e4. https://doi.org/10.1016/j.cub.2020.05.072

Saveer AM, Pitts RJ, Ferguson ST, Zwiebel LJ (2018) Characterization of chemosensory responses on the labellum of the malaria vector mosquito. Anopheles coluzzii Sci Rep 8:5656. https://doi. org/10.1038/s41598-018-23987-y

Schultze A, Breer H, Krieger J (2014) The blunt trichoid sensillum of female mosquitoes, Anopheles gambiae: odorant binding protein and receptor types. Int J Biol Sci 10:426-437. https:// doi.org/10.7150/ijbs.8754
Schultze A, Pregitzer P, Walter MF et al (2013) The Co-expression pattern of odorant binding proteins and olfactory receptors identify distinct trichoid sensilla on the antenna of the malaria mosquito Anopheles gambiae. PLoS ONE 8:1-14. https://doi. org/10.1371/journal.pone.0069412

Scialò F, Hansson BS, Giordano E et al (2012) Molecular and functional characterization of the odorant receptor2 (OR2) in the tiger mosquito Aedes albopictus. PLoS ONE 7:e36538. https://doi. org/10.1371/journal.pone.0036538

Sengul MS, Tu Z (2008) Characterization and expression of the odorantbinding protein 7 gene in Anopheles stephensi and comparative analysis among five mosquito species. Insect Mol Biol 17:631-645. https://doi.org/10.1111/j.1365-2583.2008.00837.x

Sengul MS, Tu Z (2010) Expression analysis and knockdown of two antennal odorant-binding protein genes in Aedes aegypti. J Insect Sci 10:1-18. https://doi.org/10.1673/031.010.14131

Seyfarth M, Khaireh BA, Abdi AA et al (2019) Five years following first detection of Anopheles stephensi (Diptera: Culicidae) in Djibouti, Horn of Africa: populations established-malaria emerging. Parasitol Res 118:725-732. https://doi.org/10.1007/s00436-01906213-0

Shankar S, Mcmeniman CJ (2020) An updated antennal lobe atlas for the yellow fever mosquito Aedes aegypti. PLOS Neglected Tropical Diseases 14(10):e0008729. https://dx.plos.org/10.1371/ journal.pntd.0008729

Silberbush A, Markman S, Lewinsohn E et al (2010) Predator-released hydrocarbons repel oviposition by a mosquito. Ecol Lett 13:11291138. https://doi.org/10.1111/j.1461-0248.2010.01501.x

Silbering AF, Galizia CG (2007) Processing of odor mixtures in the Drosophila antennal lobe reveals both global inhibition and glomerulus-specific interactions. J Neurosci 27:11966-11977. https://doi.org/10.1523/JNEUROSCI.3099-07.2007

Sparks JT, Bohbot JD, Dickens JC (2014) The genetics of chemoreception in the labella and tarsi of Aedes aegypti. Insect Biochem Mol Biol 48:8-16. https://doi.org/10.1016/j.ibmb.2014.02.004

Su CYY, Menuz K, Reisert J, Carlson JR (2012) Non-synaptic inhibition between grouped neurons in an olfactory circuit. Nature 492:66-71. https://doi.org/10.1038/nature11712

Su CY, Martelli C, Emonet T, Carlson JR (2011) Temporal coding of odor mixtures in an olfactory receptor neuron. Proc Natl Acad Sci U S A 108:5075-5080. https://doi.org/10.1073/pnas.1100369108

Su MP, Andrés M, Boyd-Gibbins N et al (2018) Sex and species specific hearing mechanisms in mosquito flagellar ears. Nat Commun 9 https://doi.org/10.1038/s41467-018-06388-7

Suh E, Bohbot JD, Zwiebel LJ (2014) Peripheral olfactory signaling in insects. Curr Opin Insect Sci 6:86-92. https://doi.org/10.1016/j. cois.2014.10.006

Sun H, Liu F, Baker A, Zwiebel LJ (2020a) Neuronal odor coding in the larval sensory cone of Anopheles coluzzii: Complex responses from a simple system. bioRxiv 2020.09.09.290544. https://doi. org/10.1101/2020.09.09.290544

Sun H, Liu F, Ye Z, et al (2020b) Mutagenesis of the orco odorant receptor co-receptor impairs olfactory function in the malaria vector Anopheles coluzzii. bioRxiv 2020.09.04.283424. https:// doi.org/10.1101/2020.09.04.283424

Syed Z (2002) Role of volatile chemostimuli in the sensory ecology of tsetse flies, Glossina spp., and host races of the larch bud moth, Zeiraphera diniana Guénée. PhD Dissertation, University of Neuchâtel, Switzerland

Syed Z, Guerin PM (2004) Tsetse flies are attracted to the invasive plant Lantana camara. J Insect Physiol 50:43-50. https://doi.org/10.1016/j. jinsphys.2003.09.007

Tallon AK, Hill SR, Ignell R (2019) Sex and age modulate antennal chemosensory-related genes linked to the onset of host seeking in the yellow-fever mosquito, Aedes aegypti. Sci Rep 9:1-13. https:// doi.org/10.1038/s41598-018-36550-6 
Taparia T, Ignell R, Hill SR, Rose Hill S (2017) Blood meal induced regulation of the chemosensory gene repertoire in the southern house mosquito. BMC Genomics 18:393. https://doi.org/10.1186/ s12864-017-3779-2

Task D, Lin C-C, Afify A et al (2020) Widespread polymodal chemosensory receptor expression in Drosophila olfactory neurons. bioRxiv 2020.11.07.355651. https://doi.org/10.1101/2020.11.07.355651

Tauxe GM, Macwilliam D, Boyle SM et al (2013) Targeting a dual detector of skin and $\mathrm{CO}_{2}$ to modify mosquito host seeking. Cell 155:13651379. https://doi.org/10.1016/j.cell.2013.11.013

Trible W, Olivos-Cisneros L, McKenzie SK et al (2017) orco mutagenesis causes loss of antennal lobe glomeruli and impaired social behavior in ants. Cell 170:727-735.e10. https://doi.org/10.1016/j. cell.2017.07.001

Trimble RM, Wellington WG (1979) Effects of salinity on site selection by ovipositing Aedes togoi (Diptera: Culicidae). Can J Zool 57:593596. https://doi.org/10.1139/z79-069

Van Breugel F, Riffell J, Fairhall A, Dickinson MH (2015) Mosquitoes use vision to associate odor plumes with thermal targets. Curr Biol 25:2123-2129. https://doi.org/10.1016/j.cub.2015.06.046

van der Goes van Naters W (2013) Inhibition among olfactory receptor neurons. Front Hum Neurosci 7:690. https://doi.org/10.3389/fnhum. 2013.00690

Vinauger C, Lahondère C, Wolff GH et al (2018) Modulation of host learning in Aedes aegypti mosquitoes. Curr Biol 28:333-344.e8. https://doi.org/10.1016/J.CUB.2017.12.015

Vinauger C, Van Breugel F, Locke LT et al (2019) Visual-olfactory integration in the human disease vector mosquito Aedes aegypti. Curr Biol 29:1-8. https://doi.org/10.1016/j.cub.2019.06.043

Vosshall LB, Stocker RF (2007) Molecular architecture of smell and taste in Drosophila. Annu Rev Neurosci 30:505-533

Wahid I, Sunahara T, Mogi M (2003) Maxillae and mandibles of male mosquitoes and female autogenous mosquitoes (Diptera: Culicidae). J Med Entomol 40:150-158. https://doi. org/10.1603/0022-2585-40.2.150

Warren B, Lukashkin AN, Russell IJ (2010) The dynein-tubulin motor powers active oscillations and amplification in the hearing organ of the mosquito. PRSB 277:1761-1769. https://doi.org/10.1098/ rspb.2009.2355

Wilson RI (2013) Early olfactory processing in Drosophila: mechanisms and principles. Annu Rev Neurosci 36:217-241

Windmill JFC, Jackson JC, Pook VG, Robert D (2018) Frequency doubling by active in vivo motility of mechanosensory neurons in the mosquito ear. R Soc Open Sci 5 https://doi.org/10.1098/rsos.171082

Wolff GH, Lahondère C, Vinauger C, Riffell JA (2019) Neuromodulation and differential learning across mosquito species. bioRxiv. https:// doi.org/10.1101/755017

Wolff GH, Riffell JA (2018) Olfaction, experience and neural mechanisms underlying mosquito host preference. J Exp Biol 221:4. https://doi. org/10.1242/jeb.157131

Won Jung J, Baeck SJJ, Perumalsamy H et al (2015) A novel olfactory pathway is essential for fast and efficient blood-feeding in mosquitoes. Sci Rep 5:1-10. https://doi.org/10.1038/srep13444

Xia Y, Wang G, Buscariollo D et al (2008) The molecular and cellular basis of olfactory-driven behavior in Anopheles gambiae larvae. Proc Natl Acad Sci U S A 105:6433-6438. https://doi.org/10.1073/ pnas.0801007105

Xia Y, Zwiebel LJ (2006) Identification and characterization of an odorant receptor from the West Nile Virus mosquito, Culex quinquefasciatus. Insect Biochem Mol Biol 36:169-176. https:// doi.org/10.1016/j.ibmb.2005.12.003
Xiao S, Sun JS, Carlson JR (2019) Robust olfactory responses in the absence of odorant binding proteins. Elife $8 \mathrm{https} / / /$ doi.org/10.7554/ eLife.51040

$\mathrm{Xu}$ P, Choo YM, Chen Z et al (2019) Odorant inhibition in mosquito olfaction. iScience 19:25-38. https://doi.org/10.1016/j.isci.2019.07.008

Xu P, Wen X, Leal WS (2020) CO2 per se activates carbon dioxide receptors. Insect Biochem Mol Biol 117:103284. https://doi.org/10.1016/j. ibmb.2019.103284

Xu W, Cornel AJ, Leal WS (2010) Odorant-binding proteins of the malaria mosquito Anopheles funestus sensu stricto. PLoS ONE 5:e15403. https://doi.org/10.1371/journal.pone.0015403

Yan H, Opachaloemphan C, Mancini G et al (2017) An engineered orco mutation produces aberrant social behavior and defective neural development in ants. Cell 170:736-747.e9. https://doi.org/10.1016/j. cell.2017.06.051

Ye Z, Liu F, Liu N (2020) Three-dimensional structure of the antennal lobe in the Southern house mosquito Culex quinquefasciatus. Insect Sci 1744-7917:12767. https://doi.org/10.1111/1744-7917.12767

Younger MA, Herre M, Ehrlich AR et al (2020) Non-canonical odor coding ensures unbreakable mosquito attraction to humans. bioRxiv 2020.11.07.368720. https://doi.org/10.1101/2020.11.07.368720

Zacharuk RY, Yin LRS, Blue SG (1971) Fine structure of the antenna and its sensory cone in larvae of Aedes aegypti (L.). J Morphol 135:273-297. https://doi.org/10.1002/jmor.1051350303

Zelle KM, Lu B, Pyfrom SC, Ben-Shahar Y (2013) The genetic architecture of degenerin/epithelial sodium channels in Drosophila. G3 Genes. Genomes, Genet 3:441-450. https://doi.org/10.1534/g3.112.005272

Zeng F, Xu P, Leal WS (2019) Odorant receptors from Culex quinquefasciatus and Aedes aegypti sensitive to floral compounds. Insect Biochem Mol Biol 113:103213. https://doi.org/10.1101/721878

Zermoglio PF, Robuchon E, Leonardi MS et al (2017) What does heat tell a mosquito? Characterization of the orientation behaviour of Aedes aegypti towards heat sources. J Insect Physiol 100:9-14. https://doi. org/10.1016/j.jinsphys.2017.04.010

Zhang Y, Tsang TK, Bushong EA et al (2019) Asymmetric ephaptic inhibition between compartmentalized olfactory receptor neurons. Nat Commun 10 https://doi.org/10.1038/s41467-019-09346-z

Zhao Z, Tian D, Mcbride CS (2020a) Development of a pan-neuronal genetic driver in Aedes aegypti mosquitoes. bioRxiv 2020.08.22.262527. https://doi.org/10.1101/2020.08.22.262527

Zhao Z, Zung JL, Kriete AL et al (2020b) Chemical signatures of human odour generate a unique neural code in the brain of Aedes aegypti mosquitoes. bioRxiv 2020.11.01.363861. https://doi.org/10.1101/2020.11.01.363861

Zhou JJ, He XL, Pickett JA, Field LM (2008) Identification of odorantbinding proteins of the yellow fever mosquito Aedes aegypti: Genome annotation and comparative analyses. Insect Mol Biol 17:147-163. https://doi.org/10.1111/j.1365-2583.2007.00789.x

Zhou X, Rinker DC, Pitts RJ et al (2014) Divergent and conserved elements comprise the chemoreceptive repertoire of the nonblood-feeding mosquito Toxorhynchites amboinensis. Genome Biol Evol 6:28832896. https://doi.org/10.1093/gbe/evu231

Publisher's Note Springer Nature remains neutral with regard to jurisdictional claims in published maps and institutional affiliations. 